The next two sections deal with artificial insemination by donor and with the ethical situation surrounding conception in vitro. The first stresses that Artificial Insemination by Donor (AID) is here to stay, that in some couples it remains the only alternative to childlessness and that, at least for the foreseeable future, the subject will continue to attract considerable media publicity. The second section which is in fact the Galton Lecture of 1982 was delivered by $\operatorname{Dr} R$ G Edwards and describes his well-known work with Dr Patrick Steptoe. The issue is considered mainly in the historical vein and reviews subjects already well covered in the literature.

The field of genetics dominates the remainder of the symposium. There are contributions on genetic registers, screening for carriers of recessive diseases and new developments in prenatal diagnosis. Again these areas have been more than adequately covered elsewhere and little new information is added.

The reviewer must profess a preference for the final chapter dealing with the legal implications of AID, in vitro fertilisation and embryo transfer. Here, at least, there is a refreshing. albeit brief, breeze of originality and a praiseworthy attempt is made to break some new ground.

This book scarcely merits a 1983 imprimatur. However, it may prove valuable to doctors, medical students and paramedical workers who in the past have not found the time to became conversant with these important areas of work.

JOHN A LORAINE Senior Lecturer, Department of Community Medicine, The Usher Institute, Edinburgh

\section{A Guide to The Mental Health Act 1983}

Robert Bluglass, 152 pages, Edinburgh, £9.95, Churchill Livingstone, 1983

In the post-Gostin era of psychiatric legalism the density of the legal jungle, and the frequency of attendant man traps, to which the mental health professional feels himself exposed is greatly increased. A jungle guide book is here expertly provided by one who was intimately involved in the arguing out of the conceptual and semantic terrain both inside Parliament and as Chairman of the Royal College of Psychiatrists Working Party.

Professor Bluglass is a meticulous writer, well suited therefore to legal psychiatry and he displays a detailed understanding and exposition of provisions which may baffle clinical colleagues. He clearly aims to provide a pocket reference book which may act frequently as a substitute for consultation of the Act itself, although of course he correctly demurs that there is no substitute for knowledge and interpretation of the exact wording of the Act. The book is constructed, as regards major topics, to correspond approximately in order with the parts of the Act and there is occasional intelligent expansion of discussion of topics of particular importance or difticulty, for example that of 'consent to treatment'. There is a uniform layout for each topic which gives background information, a very helpful listing of changes from the previous 1959 legislation and then a statement, frequently using the exact wording of the Act, of the relevant major provisions. The text is usually accurate and unambiguous, whilst providing helpful reference lists for further reading. There is a particularly clear explanation of the intricacies of the relationship between mental health legislation and the criminal law in the chapter on mentally disordered offenders. Similar awareness of other legislation touching on the formal and informal psychiatric patient is repeatedly demonstrated in a way which, at times, develops the book into a more general psychiatric legal commentary: it also goes beyond the Act by including a useful chapter on forensic psychiatric facilities.

At times, however, on reading some of the sections, one does have the feeling that the book would be better titled ' $A$ Guide to Changes Represented by the Mental Health Act 1983'. Clearly, emphasising the ways in which the law is now different is important but, in terms of space, it is often done at the expense of greater explanation and exploration of the current provisions. Much space is also devoted, as far as some topics are concerned, to great detail of the arguments between pressure groups and interested bodies which preceded Parliamentary decisions on individual points, of which the author has intimate and personal knowledge. Lack of emphasis on explanation most clearly emerges in the treatment of Section 1 of the Act which deals with 'mental disorder' where the definition, use and relevance to other parts of the Act of the term and the four categories thereof do, in my teaching experience, give rise to considerable confusion.

A meticulous writer on legal matters would expect to be criticised meticulously, I hope. There are a small number of errors in the book. Firstly, and very unfortunately, the grounds for $\overline{\bar{c}}$. admission under Section 3 (2)(c) are? wrongly stated as '. . . for the health $\overrightarrow{\vec{\prime}}$ and safety of other persons . . . Under Sections 2 and 3 the power of the Responsible Medical Officer to 음 block discharge is said to be grounded $\frac{\bar{\rho}}{\partial}$ in the patient being 'dangerous'; it $\stackrel{\mathbb{Q}}{\mathcal{Q}}$ should be made clear that this includes being dangerous to himself. Later it is stated in relation to Section 4 that, $\vec{O}$ under the common law doctrine of $\vec{\overrightarrow{ }}$ 'necessity', urgent treatment can be $\vec{\omega}$ given without consent to 'relieve? serious suffering'. Although some uncertainty surrounds 'necessity' this is probably not true and serious $-\vec{T}$ danger to life is probably the appropriate basis. There is also an error $\vec{\sigma}$ and a confusion over consent to treatment. It is repeatedly wrongly stated that 'informed consent' is the required standard, perhaps because the $\vec{\sim}$ book went to press before the recent $\overparen{D}$ cases of Sidaway $v$ Bethlem Royal and Maudsley Hospitals and Freeman $v$ Home $\frac{\mathbb{D}}{3}$ Office where it was confirmed that only basic or real consent is required. Also, although rightly stated elsewhere in the $\overrightarrow{0}$ text, it is said that Section 62 (urgent or treatment) refers to both formal and informal patients. Space precluctos exploration of this error but it does give rise to incorrect viewing of the legal $\bar{\partial}$ justification for emergency treatment of informal patients, which is entirely $\mathbb{Q}$ common law in origin. The author then goes on to give guidelines for interpreting the competency criteria given in the Act. It should be made clear that, in an area recognised by the Mental Health Act Commission to be fraught with conceptual difficulties, these are statements of author opinion having no legal basis.

These few criticisms aside I strongly recommend Professor Bluglass's jungle guide book.

$$
\begin{array}{r}
\text { NIGEL L G EASTMAN } \\
\text { Senior Registrar, } \\
\text { Department of Forensic Psychiatry } \\
\text { Institute of Psychiatry, London } N
\end{array}
$$

\section{Moral Dilemmas in Medicine}

Alastair V Campbell, 179 pages, Edinburgh, London, Melbourne, New York, £4.95, Churchill Livingstone, Third Edition, 1984

The fact that this is the third edition of Dr Campbell's book speaks for itself. $\frac{\text { (D) }}{\mathbb{D}}$ $\mathrm{He}$ is widely recognised as having? written a short, clear readable book which discusses a number of moralo 
dilemmas in medicine and relates them to the central theories of moral philosophy. The new edition has extended and updated the references and added a section on recommended reading for those - let us hope an increasing number - who wish to study the subject in greater depth. Although the book contains many examples from different areas of medical practice it is not padded out with over-elaborate descriptions of actual cases. Likewise the discussions of philosophers or theologians, while not superficial, do not contain more detail than would be found helpful by a busy clinician or general practitioner. The last chapter in the book deals with a few current problems. Many are mentioned and four discussed in more detail-abortion, death and dying, control of clinical research and organ transplantation. These are, of course, matters of continuing importance, but in the next edition of his book he might consider adding a lengthier discussion of the radical challenge mounted by Ivan Illich - that Western, science-based medicine does not make for the enhancement of health. There is a tendency in the medical profession to dismiss the radical challenge, but increasing numbers of ordinary people are becoming disenchanted with 'professional' scientific medicine and turning elsewhere. But medical education does not change in its essentials. It has however changed sufficiently to make this book an acceptable text for medical ethics courses.

R S DOWNIE

Professor of Moral Philosophy, Glasgow

University

\section{Respect for Life, a Symposium}

Christian Medical Fellowship, 157 Waterloo Road, London SE1 8XN

47 pages, £1.25, 1984

This brief symposium encapsulates the main attitudes to what the first contributor calls 'a vast increase in medical-moral problems and a crisis of the first magnitude in medical ethics'. The contributor is the late Dr Ian Ramsey, Bishop of Durham, who was an outstanding philosopher and ethicist. It is a paper which he wrote for the Annual Clinical Meeting of the British Medical Association in Cyprus in 1972, and is a classic writing which it is very useful to have reprinted. $\mathrm{He}$ describes the ethical crisis as 'the medical version of the general problem of giving a moral direction to applied science in a society where traditional moral absolutes are being questioned, the general problem of ensuring a humane and not a tyrannical technology, at a time when society lacks a common morality'. He asks what in fact are the prima facie medical concerns if one teases out the pre-suppositions, implicit as well as explicit, in medical papers; and by a carefully built up argument he concludes that they amount to 'a respect for human life of $a$ certain quality in society'. He points out that difficult decisions involving judging one kind of human life to be better than another, from which we might well shrink, cannot be avoided because practical situations with limited resources compel them. In general no simple decisions can be made by one medical man alone, still less solely by politicians or financiers; they require consultative trans-disciplinary groups to illuminate them, and in the course of their work to develop multi-parameter scoring and a multiple criterion. In discussing suffering, and the significance of death, Ramsey introduces Christian considerations, but the general argument does not involve them and is an illustration of the important point that the method of Christian ethics is no different from that of philosophical ethics.

The other three contributions to the symposium are shorter, and they are all concerned with the bearing of increased dependence on medical technology on our understanding of humaneness. $\mathrm{Mr}$ D B Millar, a consultant obstetrician and gynaecologist in Sheffield, shows how fetal worth is already related to gestational age in both medicine and law; and that the details of desirable laws or professional codes cannot be derived directly from Biblical texts. Professor Gareth Jones of Otago, New Zealand (Anatomy) discusses the same area of ethical issues as the Warnock Report. He is cautiously in favour of in vitro fertilisation (IVF) but against research on embryos (unlike Millar who is in favour of it), and therefore against the guidelines for research on IVF and embryo transfer (ET) issued by the Medical Research Council (MRC) in 1982 , as not showing enough respect for human embryos; though he takes issue with the moralist Paul Ramsey as being too restrictive. The most conservative position is that of Professor David Short of Aberdeen (Clinical Medicine), who explains why the Arthur case caused him to change his mind about the management of handicapped neonates. But his three reasons are not very cogent in the light of the previous contributions. (1) Human life should always be preserved provided undue suffering can be avoided. All the dilemmas are hidden in the word 'undue'. Short thinks the kind of decision Ramsey says we cannot avoid making too subjective to make. (2) It is a volte face compared with the Hippocratic tradition. But this is a purely individualistic one as concerning doctor and patient, not society. (3) We must show utmost respect for human life from conception. He and Gareth Jones use the 'wedge argument'; fear of what will happen if an absolute position is not maintained. This is not a satisfactory position. It is true that 'boundary situations' do arise where an absolute position is called for; but most moral decisions are in 'grey areas' where moral wisdom is needed for careful discernment. This is what Ian Ramsey was exploring.

The fact that this symposium is brief should not cause it to be overlooked. It is thoughtful and was well worth putting together.

RONALD PRESTON Professor Emeritus, Faculty of Theology, Manchester University

\section{A Time to Die}

Robert G Twycross, 32 pages, London $60 \mathrm{p}$, Christian Medical Fellowship, 1984

'Today's dying - and their fellow travellers, the bereaved - are today's lepers: unwanted shunned, ignored': writes Robert Twycross in this short booklet, which has the aim of overcoming this approach by society to dying patients. He writes as a Christian and a hospice physician with many years experience of caring for dying patients. He argues that the dying patient and his family should be cared for as 'whole persons' so that the time left can be used for living.

He first describes how in present-day society most people are divorced from death and this may exaggerate the natural fear of death. To care for the dying it is necessary to remain alongside the patient, but this may cause many stresses. These are due to the natural unease of death, the cultural collective fear of dying, especially of cancer, and the ensuing feelings of helplessness. However, he emphasises, using patients' histories, that although facing up to death may be disturbing, it is possible to adjust to the series of losses involved in dying. This may mean the professional coping with both the cries 